\title{
Cardiopulmonary laboratory biomarkers in the evaluation of acute dyspnea
}

\author{
This article was published in the following Dove Press journal: \\ Open Access Emergency Medicine \\ 17 May 2016 \\ Number of times this article has been viewed
}

\author{
Natalie R Stokes' \\ Brett W Dietz' \\ Jackson J Liang ${ }^{2}$ \\ 'Perelman School of Medicine, \\ University of Pennsylvania, \\ ${ }^{2}$ Cardiovascular Division, Hospital \\ of the University of Pennsylvania, \\ Philadelphia, PA, USA
}

Correspondence: Natalie R Stokes Department of Medicine, Hospital of the University of Pennsylvania, 3400 Spruce Street, Philadelphia, PA 19104, USA

Email stokesna@uphs.upenn.edu

\begin{abstract}
Dyspnea is a common chief complaint in the emergency department, with over 4 million visits annually in the US. Establishing the correct diagnosis can be challenging, because the subjective sensation of dyspnea can result from a wide array of underlying pathology, including pulmonary, cardiac, neurologic, psychiatric, toxic, and metabolic disorders. Further, the presence of dyspnea is linked with increased mortality in a variety of conditions, and misdiagnosis of the cause of dyspnea leads to poor patient-level outcomes. In combination with the history and physical, efficient, and focused use of laboratory studies, the various cardiopulmonary biomarkers can be useful in establishing the correct diagnosis and guiding treatment decisions in a timely manner. Use and interpretation of such tests must be guided by the clinical context, as well as an understanding of the current evidence supporting their use. This review discusses current standards and research regarding the use of established and emerging cardiopulmonary laboratory markers in the evaluation of acute dyspnea, focusing on recent evidence assessing the diagnostic and prognostic utility of various tests. These markers include brain natriuretic peptide (BNP) and N-terminal prohormone (NT-proBNP), mid-regional peptides proatrial NP and proadrenomedullin, cardiac troponins, D-dimer, soluble ST2, and galectin 3, and included is a discussion on the use of arterial and venous blood gases.
\end{abstract}

Keywords: cardiopulmonary, emergency, heart failure, troponin, BNP, galectin 3, MR-proANP, MR-proADM

\section{Introduction}

Dyspnea is defined as the "subjective experience of breathing discomfort that consists of qualitatively distinct sensations that vary in intensity" by the American Thoracic Society. ${ }^{1}$ A normal physiologic response to intense exertion, dyspnea becomes pathological when experienced outside of this context. It is the chief complaint for approximately 4 million emergency department (ED) visits annually in the US, comprising 3.5\% of all ED visits. ${ }^{2,3}$ Despite being a subjective symptom, dyspnea has been strongly tied to illness severity, morbidity, and mortality. Dyspnea has been found to be more closely associated with cardiac mortality than angina, ${ }^{4}$ and the most potent predictor of mortality in patients with chronic lung disease. ${ }^{5}$

A wide variety of distinctive mechanisms can result in the common sensation of dyspnea. The presentation of acute dyspnea requires a quick and focused workup to establish the appropriate diagnosis. Misdiagnosis has been shown to increase morbidity, cost, and time to discharge. ${ }^{6}$ Various laboratory studies can be used in the evaluation of acute dyspnea, and many new markers are being examined for their utility in this capacity. Appropriate use of studies can help to decrease time to diagnosis, 
make treatment decisions, properly assess risk, and reduce overall costs. The following is a review of current standards and research regarding the use of laboratory markers in the evaluation of acute dyspnea.

\section{Brain natriuretic peptide}

Brain natriuretic peptide (BNP) was first isolated in 1988, ${ }^{7}$ and quickly garnered excitement in the field of heart failure (HF). In the mid-1990s, the introduction of an inexpensive assay allowed for the use of natriuretic peptide (NP) levels as a diagnostic tool for HF in clinical practice, approved by the US Food and Drug Administration in 2000 as an adjunct for HF diagnosis. ${ }^{8}$ BNP and the N-terminal prohormone of BNP (NT-proBNP) are currently the gold standard for diagnosis of $\mathrm{HF}$ in patients presenting with acute-onset dyspnea.

BNP is one of three major NPs, with atrial NP (ANP) and C-type NP. Each functions to maintain circulatory homeostasis. BNP is primarily synthesized and secreted from the ventricular myocardium, although in pathologic states it can be synthesized in both the atrial and ventricular chambers. Both ANP and BNP induce vasodilation, natriuresis, and diuresis in an effort to oppose the renin-angiotensinaldosterone system and ameliorate stress from increased volume on the heart. ANP is stored in granules and readily released, whereas BNP undergoes transcription and synthesis in response to stressors, requiring more intense and prolonged stress to elevate circulating levels. ${ }^{9}$ BNP thus serves as an excellent marker of pathologic ventricular wall distention and cardiac pressures. ${ }^{10}$

Increased wall stress in the ventricles results in the synthesis of pre-proBNP, which undergoes two cleavages to form biologically active $\mathrm{BNP}_{1-32}$ and the inactive aminoterminal fragment NT-proBNP. Both BNP and NT-proBNP are used clinically, with similar outcomes; however, they are not interchangeable assays. NT-proBNP has a longer halflife (1-2 hours) compared with BNP (20 minutes), resulting in less fluctuation and higher overall NT-proBNP levels in the blood. The primary mechanism of clearance for BNP is neutral endopeptidase, with additional clearance conducted by NP receptors and the renal system, while NT-proBNP is primarily cleared renally. ${ }^{11}$ Despite this difference, data demonstrate that both BNP and NT-proBNP are cleared equally by the kidneys. ${ }^{12}$ The role of neutral endopeptidase in metabolizing BNP, but not NT-proBNP, can have a different impact on the levels of circulating biomarkers. Importantly, neutral endopeptidase inhibitors provide a promising therapy for HF patients and are being increasingly used in clinical practice. ${ }^{12}$ Patients enrolled in this study taking the neutral endopeptidase inhibitors were found to have reduced levels of NT-proBNP in correlation with clinical improvement; BNP levels, however, did not reduce, due to the decreased metabolism by neutral endopeptidase. As the use of neutral endopeptidase inhibitors increases, it will become difficult to interpret BNP levels, and this should be taken into consideration.

Both levels can be measured on a point-of-care testing device that allows for results within 20 minutes (Alere Triage; Hoffman-La Roche Ltd, Basel, Switzerland). Results from point-of-care testing have been shown to correlate with standard laboratory assays, and all available assays have proved significantly and independently predictive of HF. ${ }^{11}$ Availability of assays is institution-dependent.

Studies showing the validity and efficacy of BNP and NT-proBNP have been incorporated into common practice over the past decade. Early trials suggested that BNP testing was both sensitive and specific in an urgent-care setting. ${ }^{13,14}$ In 2002, the landmark Breathing Not Properly study found that using a cutoff of $100 \mathrm{pg} / \mathrm{mL}$, BNP values were significantly sensitive and specific, with strong negative and positive predictive values: at $90 \%, 73 \%, 90 \%$, and $75 \%$, respectively. Importantly, the number of patients in the ED for whom the clinician was uncertain of diagnosis was reduced from $43 \%$ with clinical assessment alone to $11 \%$ with the inclusion of BNP. ${ }^{15,16}$ The 2005 PRIDE study confirmed similar efficacy for NT-proBNP. ${ }^{17}$ Many largescale trials have provided further support of the diagnostic validity of the NPs, including the ICON, HFinCH, BASEL, and IMPROVE-CHF studies. ${ }^{17-20}$

Investigations into the impact of the use of NPs as biomarkers for evaluation of dyspnea have shown significant cost reduction. The IMPROVE-CHF study demonstrated that NP testing for management of patients presenting to the ED with dyspnea improved cost savings (average of $15 \%$ ), time to diagnosis, and selected outcomes. ${ }^{18}$ The cost savings of NP use in the ED have been validated; ${ }^{21}$ however, whether NP testing has any impact on outcomes is debated. Meta-analyses of outcomes of NP testing for patients with dyspnea of suspected cardiac origin have found moderate reduction in length of hospital stay and time to discharge, but no significant impact on admission rates, secondary admission, or mortality. ${ }^{21,22}$

Further investigations have focused on the prognostic value of NP levels. ${ }^{18,19}$ Patients with BNP levels $\geq 1,730 \mathrm{pg} / \mathrm{mL}$ had in-hospital mortality three times greater than those with BNP levels $<430 \mathrm{pg} / \mathrm{mL}$. Harrison et al found that $54 \%$ of patients with a $\mathrm{BNP} \geq 480 \mathrm{pg} / \mathrm{mL}$ at time of pre- 
sentation had subsequent HF exacerbations within 6 months; likewise, patients with a BNP $\geq 230 \mathrm{pg} / \mathrm{mL}$ or greater had a relative risk of 7.0 for future HF events. ${ }^{23}$ There is ongoing study into the use of NPs for therapeutic management. The PROTECT study found therapy guided by targets for reduction of NT-proBNP by $30 \%$ or to $<1,000 \mathrm{pg} / \mathrm{mL}$ was superior to standard-of-care HF management. ${ }^{24}$

The 2015 European Society of Cardiology/European Respiratory Society guidelines for the diagnosis and treatment of pulmonary hypertension recommend the use of BNP and NT-proBNP to assess risk for patients with pulmonary arterial hypertension. While these biomarkers are nonspecific and thus less useful for diagnosing pulmonary arterial hypertension, they are helpful for prognostication in their capacity as markers of myocardial stretch. ${ }^{25,26}$

The variety of factors that can alter BNP makes a discrete cutoff value difficult to determine, and highlights the continued importance of clinical acumen in ordering and interpreting NP results. For unclear reasons, NP levels increase with age, ${ }^{27,28}$ independently of age-related diastolic dysfunction. ${ }^{29}$ NT-proBNP is more significantly impacted by age than BNP, and thus recommended cutoff values for NT-proBNP are age-adjusted. Female sex is also associated with higher levels of circulating NPs. Studies have suggested there is a potential association with estrogen ${ }^{28}$ and an inverse relationship between testosterone and NP levels, ${ }^{30}$ although this remains unconfirmed.

Renal disease can result in elevated systemic pressures and decreased filtration and excretion. ${ }^{31}$ BNP levels elevate with an approximate glomerular filtration rate $<60 \mathrm{~mL} / \mathrm{min} / \mathrm{m}^{2}$. Despite increases with renal dysfunction, both BNP and NTproBNP maintain their diagnostic utility. ${ }^{16,17}$ Higher cutoff points for these patients have been suggested. ${ }^{16,17,32}$ Of note, hemodialysis decreases but does not completely clear BNP or NT-proBNP levels. ${ }^{33}$

Diabetes has been associated with higher NP levels, ${ }^{34,35}$ and elevated NT-proBNP may be predictive of cardiovascular events and death. ${ }^{36-38}$ Patients with chronic HF have elevated baseline BNPs. NP levels remain useful for ruling out an acute HF decomposition in this subset of patients. ${ }^{11,17,39}$ Likewise, the diagnostic and negative predictive values of the tests are maintained with all cardiac comorbidities.

There is a great deal of interest in the potential use of NPs as markers of coronary artery disease, as some have suggested that NPs are produced with ischemia independently of ventricular wall stress. The extent of coronary artery disease has been correlated with increased NPs, and increased levels at presentation with acute coronary syndrome (ACS) have been associated with increased morbidity. ${ }^{40,41}$
Pulmonary disease can elevate NP levels to a lesser extent. ${ }^{15}$ In the Breathing Not Properly study, patients with both HF and pulmonary disease had markedly higher BNP levels than those with pulmonary disease alone $(587 \mathrm{pg} / \mathrm{mL}$ vs $109 \mathrm{pg} / \mathrm{mL}) .{ }^{16}$ High-output states, such as cirrhosis, sepsis, and severe hyperthyroidism, similarly place strain on the heart via hyperdynamic stress. Elevation of BNP levels in the setting of sepsis is a reliable indicator of development of sepsis-induced cardiac depression. ${ }^{42}$ Investigations into the prognostic value of NPs in the setting of sepsis and cirrhosis are ongoing.

Factors that depress NP levels include obesity, flash pulmonary edema, and pericardial constriction. Increased body mass index has an inverse relationship with BNP and NT-proBNP in patients both with and without HF, and has been reproduced across different cultural settings. ${ }^{27,43-45}$ Using a threshold of $100 \mathrm{pg} / \mathrm{mL}$, Daniels et al showed that $20 \%$ of obese patients with HF obtained false-negative BNP results. This group suggested a cutoff value of $54 \mathrm{pg} / \mathrm{mL}$ for BNP for patients with body mass index $\geq 35 \mathrm{~kg} / \mathrm{m}^{2}$. Interestingly, they also found that a higher lean mass was more strongly correlated with increased NP levels than body mass index. Therefore, they suggest using a cutoff of $170 \mathrm{pg} / \mathrm{mL}$ in patients with high lean body mass to increase specificity. ${ }^{45,46}$

In the setting of acute cardiogenic flash pulmonary edema (particularly when onset of symptoms is less than 1 hour), the transcription and release of BNP has not had time to establish an appropriate response to the sudden increased stressor. For these patients, clinical suspicion of HF should supersede NP levels. Pericardial constriction, likewise, can cause significant symptoms in the setting of normal BNP levels, due to the absence of myocardial stretch.

Lastly, patient medications should be considered when interpreting NP levels. The chronic use of $\beta$-blockers and angiotensin-receptor blockers may reduce levels of NPs in patients with $\mathrm{HF}^{47,48}$

Current recommendations for use of NPs in the acute setting for patients presenting with dyspnea emphasize that for both BNP and NT-proBNP assays the sensitivity is greater than the specificity. Therefore, it is most useful for ruling out $\mathrm{HF}$ in patients with low-to-intermediate pretest probability. ${ }^{49,50}$ Both the American Heart Association and American College of Cardiology endorse a class IIA recommendation for the use of NPs. To date, there has not been an easily identifiable optimum cutoff value for ruling HF in or out. Current recommendations from the American College of Emergency Physicians, as well as suggestions for different cutoff points for specific patient populations, are listed 
Table I Suggested natriuretic peptide cutoff values for acute decompensated heart failure

\begin{tabular}{lllll}
\hline & & $\begin{array}{l}\text { ACEP } \\
\text { recommendation }\end{array}$ & CKD & $\begin{array}{l}\text { BMI } \\
>\mathbf{3 5} \mathbf{k g} / \mathbf{m}^{\mathbf{2}}\end{array}$ \\
\hline Exclude & & & & \\
& BNP & $<100$ & $<200^{5}$ & 54 \\
& NTproBNP & $<300$ & $<300^{21}$ & NA \\
Identify & & & NA \\
& BNP & $>500$ & & \\
& NTproBNP & & $>1,200^{6}$ & NA \\
& $<50$ years & $>450$ & $>4,502^{6}$ & NA \\
& $50-75$ years & $>900$ & & NA \\
\hline
\end{tabular}

Note: ACEP recommendations. ${ }^{110}$

Abbreviations: ACEP, American College of Emergency Physicians; NT-proBNP, $\mathrm{N}$-terminal prohormone brain natriuretic peptide; NA, not applicable; BNP, brain natriuretic peptide; CKD, chronic kidney disease; BMI, body mass index.

in Table 1. BNP levels have been shown to correlate with severity of disease, which is helpful for risk stratification. Serial testing of patients, however, has not been shown to impact clinical practice, and is not suggested. ${ }^{51}$ Likewise, routine testing of BNP in the ED does not improve diagnosis, costs, or outcomes in patients with dyspnea, and thus a clinical indication for testing is vital. The utility of NPs in diagnosis of HF is well founded; however, its function with respect to other clinical conditions is still under investigation, with no clear recommendations at this time. Due to the many factors that can influence NP levels, it is important to interpret results cautiously.

\section{Mid-regional peptides: MR-proANP and MR-proADM}

ANP is released from the atria in response to increased atrial stretch, and has diuretic, natriuretic, and vasodilatory effects. ${ }^{52}$ Adrenomedullin (ADM), released from a multitude of tissues, also has potent vasodilatory, hypotensive, and natriuretic effects. Clinical use has been limited by a lack of stability in vitro. Measurement of the stable, mid-regional (MR) prohormones of these peptides (MR-proANP and MRproADM) is now possible, and studies have investigated their ability to provide diagnostic and prognostic information for patients presenting with acute dyspnea to the ED. ${ }^{53}$

A large, multicenter prospective study demonstrated noninferiority of MR-proANP (cutoff point $\geq 120 \mathrm{pmol} / \mathrm{L}$, sensitivity $97 \%$, specificity $59.9 \%$, accuracy $73.6 \%$ ) to BNP (cutoff point $\geq 100 \mathrm{pg} / \mathrm{mL}$, sensitivity $95.6 \%$, specificity $61.9 \%$, accuracy $72.7 \%$ ) for the diagnosis or exclusion of acute HF in patients presenting to the ED with dyspnea (Table 1). This study also found that MR-proADM was superior to BNP or NT-proBNP in identifying dyspneic patients with acute decompensated HF (ADHF) at high risk of 90-day mortality. ${ }^{54} \mathrm{MR}$-proANP levels have been shown to predict $\mathrm{ADHF}$ independently from $\mathrm{BNP}$, and may therefore provide additional diagnostic value. Those with elevated MR-proANP or MR-proADM levels have markedly reduced survival. ${ }^{55}$ While the diagnostic and prognostic potential for MR-proANP, MR-proADM, and NPs are promising, at this current time, their clinical utility remains unclear, and further studies are necessary before they should be used routinely. ${ }^{56}$

\section{Galectin 3}

Gal-3 is a member of the $\beta$-galactoside-binding lectin family of protein biomarkers found in a variety of tissues. It plays an established role in the pathophysiology of many cancers; its role in HF has recently garnered more attention. Expression of Gal-3 is associated with adverse remodeling via activated cardiac fibroblasts and macrophages. ${ }^{57}$ Blood levels of Gal-3 are independently predictive of recurrent decompensations and death in patients with HF. The prognostic value of Gal-3 is additive with NP levels. ${ }^{58}$ Current American Heart Association/American College of Cardiology Foundation HF guidelines give a class IIB indication for the use of a Gal-3 assay for additive risk stratification in patients with established HF. ${ }^{59}$ Recent studies, however, have not replicated the significance of the prognostic power of Gal-3. ${ }^{60}$

NT-pro-BNP is superior to Gal-3 for identifying HF, as elevated Gal-3 is not specific for cardiac pathology. Gal-3 levels are directly associated with relative wall thickness, and inversely related to peak oxygen consumption and 6-minute walking distance. ${ }^{61}$ Gal-3 is also common to systemic inflammatory processes, including pneumonia and sepsis, ${ }^{62}$ and is upregulated in fibrosis of the liver, lung, and kidney. Elevations of Gal-3 have been used as a diagnostic marker for a variety of cancers, as well as idiopathic pulmonary fibrosis. Additionally, Gal-3 levels do not correlate with the severity of dyspnea classified by the New York Heart Association functional classification, which further limits its diagnostic value. ${ }^{58}$

Gal-3 has been under investigation for use as a marker for increased HF risk in the general population. In a population-based study of 8,000 patients over 10 years, Gal-3 was predictive of all-cause mortality, but was not specifically correlated with cardiovascular death. ${ }^{57}$ Ho et al established an increased risk of HF in the general population with high levels of Gal-3. The investigators did not recommend routine 
screening of Gal-3, however, as testing did not significantly improve overall discrimination of risk in the general population. ${ }^{63}$ A recent study found elevations in Gal-3 to be correlated with increased risk of $\mathrm{HF}$ and cardiovascular death in patients after ACS. ${ }^{64}$ This indicates a potential role for Gal-3 monitoring in patients after ACS. Studies do not support the use of routine screening with Gal-3 at this time.

\section{Biomarkers suggesting myocardial injury}

Acute myocardial infarction (MI) is a life-threatening cause of acute dyspnea. Approximately a third of patients with acute MI - more significantly women, diabetics, and the elderly present without chest pain. These patients may have dyspnea as the sole presenting symptom, and are at risk for higher inhospital mortality. ${ }^{65}$ The use of cardiac biomarkers, particularly cardiac troponins, is critical in the diagnosis of acute MI.

Cardiac troponins I and $\mathrm{T}$ (cTnI and cTnT) are tissuespecific isoforms of regulatory proteins involved in the actin-myosin interaction of cardiac muscle, ${ }^{66}$ and they are both sensitive and specific biomarkers for detection of myocardial injury. ${ }^{67,68}$ Elevation of cardiac biomarkers $>99$ th percentile for a reference population is part of the third universal definition of MI. ${ }^{68}$

Advances in troponin assays have resulted in the development of highly sensitive assays (hs-cTn) which can detect cardiac troponin levels even in the majority of healthy individuals. The higher sensitivity of these assays has the potential advantage of allowing faster ruling in or out of acute MI, reducing the time to diagnosis. ${ }^{69}$ These tests appear to increase the accuracy of MI diagnosis, especially at 1 hour. ${ }^{70}$ While highly sensitive assays are widely used in Europe, many centers in the US continue to utilize conventional cardiac troponin assays. The 2015 European Society of Cardiology guideline algorithm for ruling out acute MI without ST elevations now requires the use of hs-cTn testing at presentation and at 3 hours, and allows for an alternative rule-out algorithm with testing at presentation and at 1 hour using hs-cTn assays with validated, assay-specific cutoff values, demonstrating the potential of these assays to reduce the time to diagnosis in the ED. ${ }^{71}$

Despite the specificity of troponins for myocardial tissue, the differential diagnosis for troponin elevation is extensive, and includes renal failure, HF, pulmonary embolism, myocarditis, arrhythmias, severe acute neurological disease, acute respiratory failure, chronic obstructive pulmonary disease (COPD), sepsis, pulmonary hypertension, and infiltrative diseases, among other disorders (Table 2) ${ }^{72}$ It is important to distinguish acute from chronic causes of troponin elevation. The current recommendation of the third universal definition of MI is to draw cardiac troponin on first assessment of patients with suspected MI, with a repeat measurement in 3-6 hours. Further measurements should be performed for additional episodes of suspected ischemia or uncertain timing of symptom onset. A rising or falling pattern with at least one value over the 99th percentile, along with strong clinical suspicion, is generally required for diagnosis of MI ${ }^{68}$ Supporting data for the diagnosis of ACS as the cause of troponin elevation include ST-segment or T-wave changes, development of pathological Q waves, and symptoms of cardiac ischemia.

Cardiac troponins may be elevated in a number of cardiopulmonary conditions that can present with dyspnea. Over a third of patients with acute pulmonary embolism have elevated troponin I, likely due to right ventricular strain. ${ }^{73}$ Though these markers are not sensitive or specific for diagnosis, elevations of troponins have been associated with a higher risk of short-term mortality. ${ }^{74}$ Undetectable levels of hs-cTn have been shown to have excellent negative predictive value for in-hospital adverse events, ${ }^{75}$ though the positive predictive value of troponin assays is quite low. ${ }^{75}$

Acute exacerbations of COPD have been linked to a fourfold elevation in troponin $\mathrm{T}$, though the mechanism underlying this elevation remains uncertain. ${ }^{77}$ The pattern of elevation is typically modest and flat, as opposed to the rising or falling pattern seen in MI. Elevation in cardiac troponin for patients with COPD exacerbations, acute respiratory distress syndrome (ARDS), and chronic pulmonary hypertension is predictive of

Table 2 Causes of elevated troponin

Myocardial infarction
Heart failure
End-stage renal disease
Pulmonary embolism
COPD
Sepsis and other critical illness
Acute cerebrovascular event
Intense exercise
Cardiac contusion
Acute pericarditis and myocarditis
Tachyarrythmias
Cardioversion
Cardiopulmonary resuscitation
Coronary vasospasm
Cardiac surgery, percutaneous coronary intervention
False-positive test

Note: Information from Inbar R, Shoenfeld $Y^{76}$

Abbreviation: COPD, chronic obstructive pulmonary disease. 
higher all-cause mortality. ${ }^{78-80}$ Many patients with acute HF will have troponin elevations above the 99th percentile even in the absence of acute MI. These elevations are also associated with increased risk of mortality, especially when a rising pattern is seen. Additionally, stably elevated troponin in patients with chronic HF is also associated with increased all-cause mortality. ${ }^{81}$ In chronic renal failure, troponins are commonly elevated. They are still the preferred biomarker for diagnosis of acute MI; however, there exists a wide range of estimates for their sensitivity and specificity in this setting. ${ }^{82}$

In summary, a number of life-threatening causes of acute dyspnea, including acute MI, ADHF, pulmonary embolism (PE), COPD exacerbation, and ARDS, among others, may have significantly elevated troponins on presentation. Many of these conditions are frequently comorbid with ischemic cardiovascular disease. Even in the absence of acute MI, troponins are markers of myocardial injury and portend a worse prognosis. The clinical context, comorbidities, baseline troponin levels, and pattern and degree of troponin rise must be taken into account in diagnosing MI as a cause of acute dyspnea.

\section{D-dimer}

Patients presenting with acute-onset dyspnea should be ruled out for PE, as it is a potentially life-threatening cause of dyspnea. Dyspnea is the most common presenting symptom of PE, and may suggest the presence of a hemodynamically significant clot.

D-dimer is a degradation product of fibrin. When normal, D-dimer is highly sensitive for excluding PE ${ }^{83}$ but the specificity of the test is poor. Multiple trials have confirmed the safety of using a clinical decision rule to determine a pretest probability of $\mathrm{PE}$ in combination with D-dimer assay to rule out PE. ${ }^{84-86}$

Pretest probability can be assessed using the Wells criteria or Geneva score, with or without the PE rule-out criteria (PERC). Both the Wells criteria and Geneva score have been simplified to enhance clinical utility. The Wells criteria have been validated using both a three-tiered grouping system (low, moderate, or high likelihood of PE), as well as a dichotomized categorization (unlikely vs likely to have PE). Similarly, the Geneva score separates patients into low-, intermediate-, and high-likelihood categories. Those patients falling into the low or intermediate categories, using the initial Wells criteria or Geneva score, or the unlikely category, using the updated Wells criteria, should be considered for a D-dimer test. ${ }^{76,87}$

For patients with low $(<15 \%)$ pretest probability of $\mathrm{PE}$, clinicians can consider using the PERC to exclude the diagnosis (level B recommendation). A patient must meet all

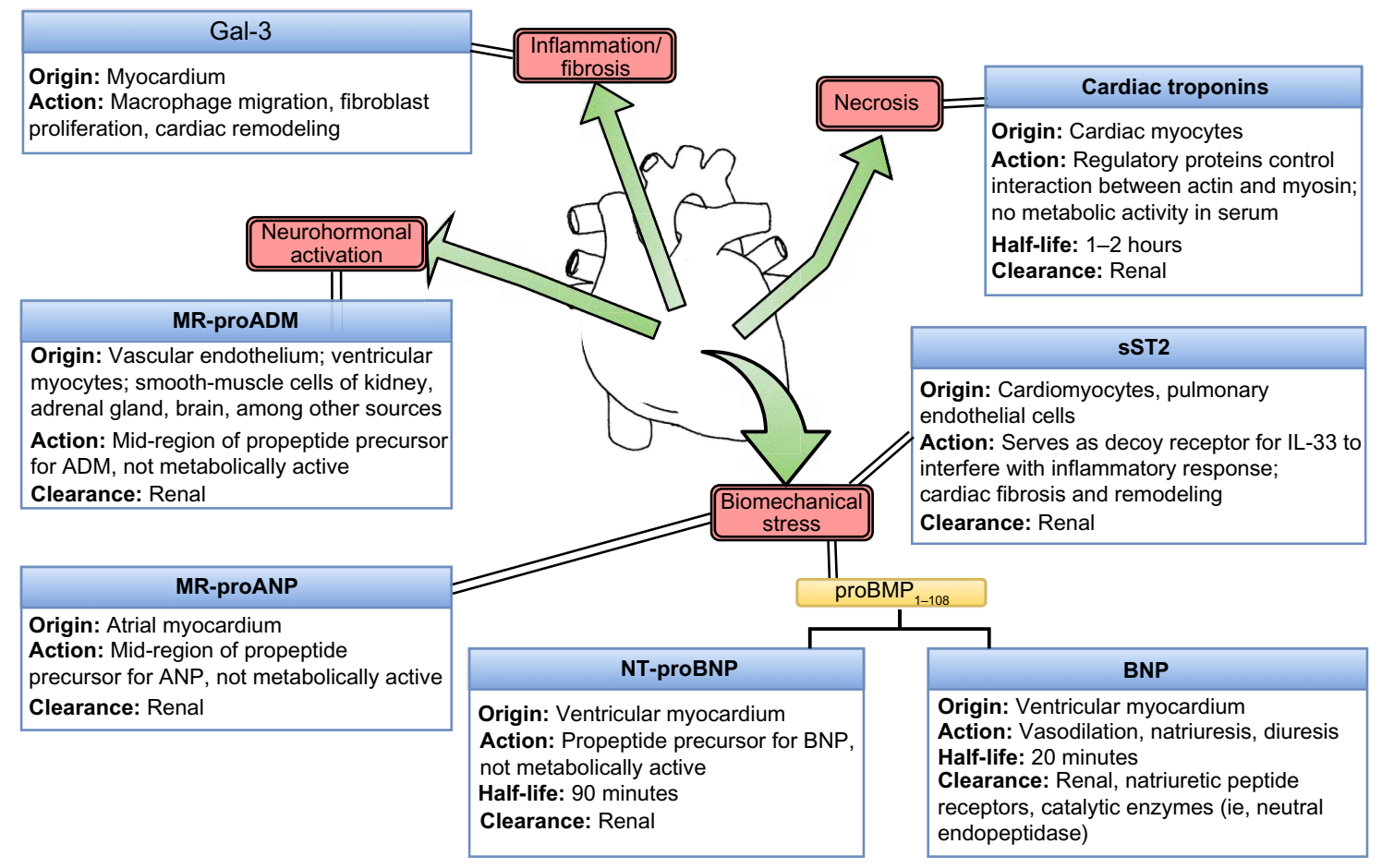

Figure I Basic pathophysiology of cardiac biomarker production.

Abbreviations: MR-proADM, mid-region prohormone adrenomedullin; ANP, atrial natriuretic peptide; sST2, soluble ST2; NT-proBNP, N-terminal prohormone brain natriuretic peptide; BNP, brain natriuretic peptide; ADM, adrenomedullin. 
eight of the PERC criteria to be ruled out for PE. D-dimer assay and PERC have not been compared systematically; D-dimer testing for ruling out PE has been more thoroughly analyzed, and is thus recommended.

Normal D-dimer levels in low-risk patients are helpful to exclude acute but not chronic PE, or incomplete resolution of prior PE(s). Likewise, D-dimer testing has been shown to have low sensitivity for small segmental PEs. ${ }^{88}$

Patients for whom the pre-test probability of PE is high should not have a D-dimer assay sent. In these patients, a normal D-dimer is not sufficient to exclude PE, and may provide false reassurance. The current diagnostic approach for patients with elevated D-dimer results is inefficient and costly, ${ }^{89}$ and honing the algorithm for diagnosis in this population is a priority.

Heterogeneity in the use of different assays is a problem for standardization and interpretation of D-dimer measurement. ${ }^{90,91}$ The most sensitive methods for measuring serum D-dimer levels are the enzyme-linked immunosorbent assay (ELISA) and turbidimetric testing. ELISAs are the reference standard, but are expensive and labor- and time-intensive, and thus impractical in an acute setting. Whole-blood assays and latex agglutination provide rapid results, and are used widely in clinical settings. Although not as sensitive as ELISA, these methods have been confirmed to be reliable when using the clinical decision rule with D-dimer testing for ruling out PE. ${ }^{92}$

Baseline D-dimer levels tend to be higher in older patients and in African-Americans. ${ }^{93}$ Additionally, acute illness, malignancy, chronic kidney disease, and rheumatoid factor can elevate D-dimer. There is a continuous increase in D-dimer throughout normal pregnancy for all gestations. There is no official consensus for how to approach D-dimer testing in these populations. The American Thoracic Society does not recommend the use of D-dimer to rule out PE in pregnant woman, with a small body of evidence indicating that a negative D-dimer assay is inadequate to rule out $\mathrm{PE}$ for these patients; however, further research is encouraged to hone these guidelines. ${ }^{94}$ For patients in each of the aforementioned populations, clinicians must incorporate consideration of these factors into assay interpretation.

For patients presenting with acute dyspnea, D-dimer is useful only for ruling out $\mathrm{PE}$ in patients who are unlikely to have PE by clinical decision. Suggestions of D-dimer for use in treatment monitoring are currently under investigation.

\section{Blood gases}

Blood gas (BG) analysis provides valuable insight into a patient's respiratory and metabolic status, including assess- ment of oxygenation, gas exchange, the need for supportive ventilation, and acid-base disorders. ${ }^{95,96}$ Guidelines for diagnosis and management of several common causes of acute dyspnea require use of the arterial $\mathrm{BG}$ (ABG). In COPD exacerbations requiring inpatient treatment, $\mathrm{ABGs}$ are useful in the initial assessment, as worsening hypoxia or hypercapnia are indications for inpatient treatment. Monitoring $\mathrm{PO}_{2}$, $\mathrm{PCO}_{2}$, and $\mathrm{pH}$ via $\mathrm{ABG}$ is a critical part of managing COPD exacerbations and determining the need for adjustments in oxygen therapy or initiating mechanical ventilation. ${ }^{97}$ Use of the $\mathrm{ABG}$ is also recommended in all patients presenting with presumed severe HF and severe cardiopulmonary disease, including ARDS. ${ }^{1,98}$

In unselected patients presenting to the ED with a chief complaint of dyspnea, ABGs drawn upon presentation provide only limited diagnostic value. With the exception of diagnosing anxiety-induced hyperventilation, ABGs are not particularly helpful in distinguishing between cardiac and pulmonary etiologies of dyspnea. However, ABGs may be helpful for prognostication, eg, $\mathrm{pH}$ independently predicts intensive care-unit admission and 12-month mortality. ${ }^{99}$

Venous BG (VBG) measurement can also be used to assess respiratory and acid-base status in the evaluation of the patient with acute dyspnea. The arterial $\mathrm{pH}$ is typically 0.03 higher than the venous $(95 \%$ prediction interval 0.029-0.038), while there is less acceptable agreement for $\mathrm{PCO}_{2}$ (95\% prediction interval -10.7 to $\left.2.4 \mathrm{mmHg}\right) .{ }^{100} \mathrm{PO}_{2}$ is obviously quite different. ${ }^{82}$ Some have suggested that when used in the correct clinical context, a venous $\mathrm{PCO}_{2}$ cutoff of $45 \mathrm{mmHg}$ may be used to screen for clinically significant hypercarbia. ${ }^{101}$ Notably, the difference in arterial and venous measurements increases substantially in patients with circulatory compromise. ${ }^{102}$ At this time, further outcome-based research is needed before recommending routine use of VBG over the $\mathrm{ABG}$.

In summary, while the $\mathrm{ABG}$ remains an important aspect of the diagnosis and management of several cardiopulmonary disorders that present with acute dyspnea, its utility in distinguishing causes of acute dyspnea is limited.

\section{ST2}

Soluble ST2 (sST2), a member of the IL-1 receptor family, is secreted into the circulation by cardiomyocytes and pulmonary endothelial cells in response to inflammatory and cardiac diseases. ${ }^{103-105}$ Upon release, sST2 inhibits IL-33/ ST2 signaling by functioning as a decoy IL-33 receptor, thus downregulating the inflammatory response. ${ }^{106}$ While sST2 levels were significantly higher in patients with acute HF than 
in those without, NT-proBNP has been shown to be superior in diagnosis of HF. ${ }^{104}$ High levels of sST2 correlate with disease severity and increased morbidity in patients with ADHF and ACS. ${ }^{106}$

Elevated levels have also been found in patients with pathologic pulmonary disease, including COPD, pulmonary hypertension, asthma, and pneumonia. ${ }^{107-109}$ In one study, sST2 concentration $\geq 0.20 \mathrm{ng} / \mathrm{mL}$ strongly predicted 1 -year mortality in patients with dyspnea (hazard ratio 5.6), and this was even more pronounced in patients with acute HF (hazard ratio 9.3). Elevated levels of sST2 in the setting of noncardiac dyspnea have been associated with poor outcomes. ${ }^{105}$

Due to its poor specificity, ST2 has limited utility in distinguishing the etiology of dyspnea. However, it does provide prognostic value for patients with $\mathrm{HF}, \mathrm{ACS}$, and potentially other cardiopulmonary processes. Further research is needed to establish the utility of ST2 use in clinical practice.

\section{Conclusion}

The laboratory assays described serve various purposes in helping to hone the diagnosis of dyspnea (Figure 1). A summary of recommendations is as follows:

The use of any laboratory assay should be based on clinical suspicion of underlying etiology based on thorough history, physical examination, and preliminary hemodynamic evaluation.

Both BNP and NT-proBNP are helpful biomarkers for identifying ADHF as the cause of acute dyspnea, and Gal-3 has shown limited diagnostic utility.

NPs, ABG, MR peptides, sST2, and Gal-3 have all demonstrated prognostic power for patients presenting with acuteonset dyspnea. Further investigation is needed to establish the most effective way to use these tests diagnostically.

Use of troponins for diagnosis of MI requires recognition of the pattern and degree of elevation. Even in the absence of acute MI, troponins are markers of myocardial injury and portend worse prognosis.

D-dimer should only be used to rule out PE in patients unlikely to have PE based on the clinical decision rule.

BGs do not have diagnostic utility in distinguishing cardiac from pulmonary causes of dyspnea in undifferentiated patients; however, $\mathrm{ABG}$ remains an important aspect of the diagnosis and management of severe cardiopulmonary disorders that present with acute dyspnea. VBG results can also be useful in assessing respiratory and acid-base status, but should be interpreted with caution, especially in patients with circulatory compromise.
Concomitant clinical considerations, including patient characteristics, medical history, medications, and possible mixed diagnoses, should always be incorporated into assay interpretation.

\section{Disclosure}

The authors report no conflicts of interest in this work.

\section{References}

1. Parshall MB, Schwartzstein RM, Adams L, et al. An official American Thoracic Society statement: update on the mechanisms, assessment, and management of dyspnea. Am J Respir Crit Care Med. 2012;185(4): 435-452.

2. Nawar EW, Niska RW, Xu J. National Hospital Ambulatory Medical Care Survey: 2005 emergency department summary. Adv Data. 2007;(386):1-32.

3. Niska R, Bhuiya F, Xu J. National Hospital Ambulatory Medical Care Survey: 2007 emergency department summary. Natl Health Stat Report. 2010;(26):1-31.

4. Abidov A, Rozanski A, Hachamovitch R, et al. Prognostic significance of dyspnea in patients referred for cardiac stress testing. $N$ Engl J Med. 2005;353(18):1889-1898.

5. Celli BR, Cote CG, Marin JM, et al. The body-mass index, airflow obstruction, dyspnea, and exercise capacity index in chronic obstructive pulmonary disease. $N$ Engl J Med. 2004;350(10):1005-1012.

6. Breidthardt T, Laule K, Strohmeyer AH, et al. Medical and economic long-term effects of B-type natriuretic peptide testing in patients with acute dyspnea. Clin Chem. 2007;53(8):1415-1422.

7. Maekawa K, Sudoh T, Furusawa M, et al. Cloning and sequence analysis of cDNA encoding a precursor for porcine brain natriuretic peptide. Biochem Biophys Res Commun. 1988;157(1):410-416.

8. Nayer J, Aggarwal P, Galwankar S. Utility of point-of-care testing of natriuretic peptides (brain natriuretic peptide and n-terminal pro-brain natriuretic peptide) in the emergency department. Int J Crit Illn Inj Sci. 2014;4(3):209-215.

9. Doust JA, Glasziou PP, Pietrzak E, Dobson AJ. A systematic review of the diagnostic accuracy of natriuretic peptides for heart failure. Arch Intern Med. 2004;164(18):1978-1984.

10. Yasue H, Yoshimura M, Sumida H, et al. Localization and mechanism of secretion of B-type natriuretic peptide in comparison with those of A-type natriuretic peptide in normal subjects and patients with heart failure. Circulation. 1994;90(1):195-203.

11. Lainchbury JG, Campbell E, Frampton CM, Yandle TG, Nicholls MG, Richards AM. Brain natriuretic peptide and $\mathrm{N}$-terminal brain natriuretic peptide in the diagnosis of heart failure in patients with acute shortness of breath. J Am Coll Cardiol. 2003;42(4):728-735.

12. van Kimmenade RR, Januzzi JL Jr, Bakker JA, et al. Renal clearance of B-type natriuretic peptide and amino terminal pro-B-type natriuretic peptide: a mechanistic study in hypertensive subjects. J Am Coll Cardiol. 2009;53(10):884-890.

13. Dao Q, Krishnaswamy P, Kazanegra R, et al. Utility of B-type natriuretic peptide in the diagnosis of congestive heart failure in an urgent-care setting. J Am Coll Cardiol. 2001;37(2):379-385.

14. Villacorta H, Duarte A, Duarte NM, et al. The role of B-type natriuretic peptide in the diagnosis of congestive heart failure in patients presenting to an emergency department with dyspnea. Arq Bras Cardiol. 2002;79(6):569-572, 564-568.

15. Morrison LK, Harrison A, Krishnaswamy P, Kazanegra R, Clopton P, Maisel A. Utility of a rapid B-natriuretic peptide assay in differentiating congestive heart failure from lung disease in patients presenting with dyspnea. J Am Coll Cardiol. 2002;39(2):202-209.

16. McCullough PA, Nowak RM, McCord J, et al. B-type natriuretic peptide and clinical judgment in emergency diagnosis of heart failure: analysis from Breathing Not Properly (BNP) multinational study. Circulation. 2002;106(4):416-422. 
17. Januzzi JL Jr, Camargo CA, Anwaruddin S, et al. The N-terminal proBNP investigation of dyspnea in the emergency department (PRIDE) study. Am J Cardiol. 2005;95(8):948-954.

18. Moe GW, Howlett J, Januzzi JL, et al. N-terminal pro-B-type natriuretic peptide testing improves the management of patients with suspected acute heart failure: primary results of the Canadian prospective randomized multicenter IMPROVE-CHF study. Circulation. 2007;115(24):3103-3110.

19. Boldanova T, Noveanu M, Breidthardt T, et al. Impact of history of heart failure on diagnostic and prognostic value of BNP: results from the B-Type Natriuretic Peptide for Acute Shortness of Breath Evaluation (BASEL) study. Int J Cardiol. 2010;142(3):265-272.

20. Mason JM, Hancock HC, Close H, et al. Utility of biomarkers in the differential diagnosis of heart failure in older people: findings from the heart failure in care homes $(\mathrm{HFinCH})$ diagnostic accuracy study. PLoS One. 2013;8(1):e53560.

21. Trinquart L, Ray P, Riou B, Teixeira A. Natriuretic peptide testing in EDs for managing acute dyspnea: a meta-analysis. Am J Emerg Med. 2011;29(7):757-767.

22. Lam LL, Cameron PA, Schneider HG, Abramson MJ, Müller C, Krum H. Meta-analysis: effect of B-type natriuretic peptide testing on clinical outcomes in patients with acute dyspnea in the emergency setting. Ann Intern Med. 2010;153(11):728-735.

23. Harrison A, Morrison LK, Krishnaswamy P, et al. B-type natriuretic peptide predicts future cardiac events in patients presenting to the emergency department with dyspnea. Ann Emerg Med. 2002;39(2):131-138.

24. Bhardwaj A, Rehman SU, Mohammed A, Baggish AL, Moore SA, Januzzi JL Jr. Design and methods of the Pro-B Type Natriuretic Peptide Outpatient Tailored Chronic Heart Failure Therapy (PROTECT) study. Am Heart J. 2010;159(4):532-538.e1.

25. Leuchte HH, El Nounou M, Tuerpe JC, et al. N-terminal pro-brain natriuretic peptide and renal insufficiency as predictors of mortality in pulmonary hypertension. Chest. 2007;131:402-409.

26. Galiè N, Humbert M, Vachiery JL, et al. 2015 ESC/ERS guidelines for the diagnosis and treatment of pulmonary hypertension: the Joint Task Force for the Diagnosis and Treatment of Pulmonary Hypertension of the European Society of Cardiology (ESC) and the European Respiratory Society (ERS). Eur Heart J. 2016;37(1):67-119.

27. Wang TJ, Larson MG, Levy D, et al. Impact of age and sex on plasma natriuretic peptide levels in healthy adults. Am J Cardiol. 2002; 90(3): 254-258.

28. Costello-Boerrigter LC, Boerrigter G, Redfield MM, et al. Aminoterminal pro-B-type natriuretic peptide and B-type natriuretic peptide in the general community: determinants and detection of left ventricular dysfunction. J Am Coll Cardiol. 2006;47(2):345-353.

29. Redfield MM, Rodeheffer RJ, Jacobsen SJ, Mahoney DW, Bailey KR, Burnett JC Jr. Plasma brain natriuretic peptide concentration: impact of age and gender. J Am Coll Cardiol. 2002;40(5):976-982.

30. Kawai, K. et al. Attenuation of biologic compensatory action of cardiac natriuretic peptide system with aging. Am J Cardiol. 2004;93(6):719-723.

31. Richards AM, Nicholls MG, Yandle TG, et al. Plasma N-terminal pro-brain natriuretic peptide and adrenomedullin: new neurohormonal predictors of left ventricular function and prognosis after myocardial infarction. Circulation. 1998;97(19):1921-1929.

32. Jafri L, Kashif W, Tai J, et al. B-type natriuretic peptide versus amino terminal pro-B type natriuretic peptide: selecting the optimal heart failure marker in patients with impaired kidney function. BMC Nephrol. 2013;14:117

33. Yang JW, Kim MS, Kim JS, et al. Relationship between serum brain natriuretic peptide and heart function in patients with chronic kidney disease. Korean J Intern Med. 2008;23(4):191-200.

34. Raymond I, Groenning BA, Hildebrandt PR, et al. The influence of age, sex and other variables on the plasma level of $\mathrm{N}$-terminal pro brain natriuretic peptide in a large sample of the general population. Heart. 2003;89(7):745-751.

35. Yano Y, Katsuki A, Gabazza EC, et al. Plasma brain natriuretic peptide levels in normotensive noninsulin-dependent diabetic patients with microalbuminuria. J Clin Endocrinol Metab. 1999;84(7):2353-2356.
36. van der Horst IC, de Boer RA, Hillege HL, Boomsma F, Voors AA, van Veldhuisen DJ. Neurohormonal profile of patients with heart failure and diabetes. Neth Heart J. 2010;18(4):190-196.

37. Winkler K, Wanner C, Drechsler C, et al. Change in N-terminal-pro-Btype-natriuretic-peptide and the risk of sudden death, stroke, myocardial infarction, and all-cause mortality in diabetic dialysis patients. Eur Heart J. 2008;29(17):2092-2099.

38. Huelsmann M, Neuhold S, Resl M, et al. PONTIAC (NT-proBNP selected prevention of cardiac events in a population of diabetic patients without a history of cardiac disease): a prospective randomized controlled trial. J Am Coll Cardiol. 2013;62(15):1365-1372.

39. Maisel AS, Krishnaswamy P, Nowak RM, et al. Rapid measurement of B-type natriuretic peptide in the emergency diagnosis of heart failure. N Engl J Med. 2002;347(3):161-167.

40. Weber M, Dill T, Arnold R, et al. N-terminal B-type natriuretic peptide predicts extent of coronary artery disease and ischemia in patients with stable angina pectoris. Am Heart J. 2004;148(4):612-620.

41. Davidson NC, Pringle SD, Pringle TH, McNeill GP, Struthers AD. Right coronary artery stenosis is associated with impaired cardiac endocrine function during exercise. Eur Heart J. 1997;18(11):1749-1754.

42. Post F, Weilemann LS, Messow CM, Sinning C, Münzel T. B-type natriuretic peptide as a marker for sepsis-induced myocardial depression in intensive care patients. Crit Care Med. 2008;36(11):3030-3037.

43. Wang TJ, Larson MG, Levy D, et al. Impact of obesity on plasma natriuretic peptide levels. Circulation. 2004;109(5):594-600.

44. Mehra MR, Uber PA, Park MH, et al. Obesity and suppressed B-type natriuretic peptide levels in heart failure. J Am Coll Cardiol. 2004;43(9):1590-1595.

45. Daniels LB, Clopton P, Bhalla V, et al. How obesity affects the cut-points for B-type natriuretic peptide in the diagnosis of acute heart failure: results from the Breathing Not Properly multinational study. Am Heart J. 2006;151(5):999-1005.

46. Madamanchi C, Alhosaini H, Sumida A, Runge MS. Obesity and natriuretic peptides, BNP and NT-proBNP: mechanisms and diagnostic implications for heart failure. Int J Cardiol. 2014;176(3):611-617.

47. Latini R, Masson S, Anand I, et al. The comparative prognostic value of plasma neurohormones at baseline in patients with heart failure enrolled in Val-HeFT. Eur Heart J. 2004;25(4):292-299.

48. Hartmann F, Packer M, Coats AJ, et al. Prognostic impact of plasma $\mathrm{N}$-terminal pro-brain natriuretic peptide in severe chronic congestive heart failure: a substudy of the Carvedilol Prospective Randomized Cumulative Survival (COPERNICUS) trial. Circulation. 2004;110(13):1780-1786.

49. Worster A, Balion CM, Hill SA, et al. Diagnostic accuracy of BNP and NT-proBNP in patients presenting to acute care settings with dyspnea: a systematic review. Clin Biochem. 2008;41(4-5):250-259.

50. Korenstein D, Wisnivesky JP, Wyer P, Adler R, Ponieman D, McGinn T. The utility of B-type natriuretic peptide in the diagnosis of heart failure in the emergency department: a systematic review. BMC Emerg Med. 2007; 7:6.

51. Singer AJ, Birkhahn RH, Guss D, et al. Rapid Emergency Department Heart Failure Outpatients Trial (REDHOT II): a randomized controlled trial of the effect of serial B-type natriuretic peptide testing on patient management. Circ Heart Fail. 2009;2(4):287-293.

52. Globits S, Frank H, Pacher B, Huelsmann M, Ogris E, Pacher R. Atrial natriuretic peptide release is more dependent on atrial filling volume than on filling pressure in chronic congestive heart failure. Am Heart J. 1998;135(4):592-597.

53. Peacock WF. Novel biomarkers in acute heart failure: MR-proadrenomedullin. Clin Chem Lab Med. 2014;52(10):1433-1435.

54. Maisel A, Mueller C, Nowak R, et al. Mid-region pro-hormone markers for diagnosis and prognosis in acute dyspnea: results from the BACH (Biomarkers in Acute Heart Failure) trial. J Am Coll Cardiol. 2010;55(19):2062-2076.

55. Shah RV, Truong QA, Gaggin HK, Pfannkuche J, Hartmann O, Januzzi JL Jr. Mid-regional pro-atrial natriuretic peptide and pro-adrenomedullin testing for the diagnostic and prognostic evaluation of patients with acute dyspnoea. Eur Heart J. 2012;33(17):2197-2205. 
56. Brunner-La Rocca HP, Sanders-van Wijk S, Knackstedt C. Biomarkers in patients with acute dyspnoea: what for? Eur Heart $J$. 2012;33(17):2124-2126.

57. de Boer RA, Yu L, van Veldhuisen DJ. Galectin-3 in cardiac remodeling and heart failure. Curr Heart Fail Rep. 2010;7(1):1-8.

58. van Kimmenade RR, Januzzi JL Jr, Ellinor PT, et al. Utility of aminoterminal pro-brain natriuretic peptide, galectin-3, and apelin for the evaluation of patients with acute heart failure. J Am Coll Cardiol. 2006;48(6):1217-1224.

59. Yancy CW, Jessup M, Bozkurt B, et al. 2013 ACCF/AHA guideline for the management of heart failure: a report of the American College of Cardiology Foundation/American Heart Association Task Force on Practice Guidelines. Circulation. 2013;128(16):e240-e327.

60. Brouwers FP, van Gilst WH, Damman K, et al. Clinical risk stratification optimizes value of biomarkers to predict new-onset heart failure in a community-based cohort. Circ Heart Fail. 2014;7(5):723-731.

61. Redfield MM, Chen HH, Borlaug BA, et al. Effect of phosphodiesterase-5 inhibition on exercise capacity and clinical status in heart failure with preserved ejection fraction: a randomized clinical trial. JAMA. 2013;309(12):1268-1277.

62. Mueller T, Leitner I, Egger M, Haltmayer M, Dieplinger B, et al. Association of the biomarkers soluble ST2, galectin-3 and growthdifferentiation factor-15 with heart failure and other non-cardiac diseases. Clin Chim Acta. 2015;445:155-160.

63. Ho JE, Liu C, Lyass A, et al. Galectin-3, a marker of cardiac fibrosis, predicts incident heart failure in the community. $\mathrm{J} \mathrm{Am} \mathrm{Coll} \mathrm{Cardiol.}$ 2012;60(14):1249-1256.

64. Magnani G, O’Donoghue M, Brunwald E, et al. Galectin-3 for heart failure risk stratification in patients after acute coronary syndromes: insights from the Solid-TIMI 52 trial. J Am Coll Cardiol. 2015;65(10 Suppl):A773.

65. Canto JG, Shlipak MG, Rogers WJ, et al. Prevalence, clinical characteristics, and mortality among patients with myocardial infarction presenting without chest pain. JAMA. 2000;283(24):3223-3229.

66. Adams JE 3rd, Abendschein DR, Jaffe AS. Biochemical markers of myocardial injury: is MB creatine kinase the choice for the 1990s? Circulation. 1993;88(2):750-763.

67. Jaffe AS, Ravkilde J, Roberts R, et al. It's time for a change to a troponin standard. Circulation. 2000;102(11):1216-1220.

68. Thygesen K, Alpert JS, Jaffe AS, et al. Third universal definition of myocardial infarction. Circulation. 2012;126(16):2020-2035.

69. Mueller C. Biomarkers and acute coronary syndromes: an update. Eur Heart J. 2014;35(9):552-556.

70. Keller T, Zeller T, Ojeda F, et al. Serial changes in highly sensitive troponin I assay and early diagnosis of myocardial infarction. JAMA. 2011;306(24):2684-2693.

71. Roffi M, Patrono C, Collet JP, et al. 2015 ESC guidelines for the management of acute coronary syndromes in patients presenting without persistent ST-segment elevation: Task Force for the Management of Acute Coronary Syndromes in Patients Presenting Without Persistent ST-Segment Elevation of the European Society of Cardiology (ESC). Eur Heart J. 2016;37(3):267-315.

72. Thygesen K, Mair J, Katus H, et al. Recommendations for the use of cardiac troponin measurement in acute cardiac care. Eur Heart J. 2010;31(18):2197-2204.

73. Meyer T, Binder L, Hruska N, Luthe H, Buchwald AB. Cardiac troponin I elevation in acute pulmonary embolism is associated with right ventricular dysfunction. J Am Coll Cardiol. 2000;36(5):1632-1636.

74. Becattini C, Vedovati MC, Agnelli G. Prognostic value of troponins in acute pulmonary embolism: a meta-analysis. Circulation. 2007;116(4): 427-433.

75. Hakemi EU, Alyousef T, Dang G, Hakmei J, Doukky R. The prognostic value of undetectable highly sensitive cardiac troponin I in patients with acute pulmonary embolism. Chest. 2015;147(3):685-694.

76. Inbar R, Shoenfeld Y. Elevated cardiac troponins: the ultimate marker for myocardial necrosis, but not without a differential diagnosis. Isr Med Assoc J. 2009;11(1):50-53.
77. Søyseth V, Bhatnagar R, Holmedahl NH, et al. Acute exacerbation of COPD is associated with fourfold elevation of cardiac troponin T. Heart. 2013;99(2):122-126.

78. Pavasini R, d'Ascenzo F, Campo G, et al. Cardiac troponin elevation predicts all-cause mortality in patients with acute exacerbation of chronic obstructive pulmonary disease: systematic review and metaanalysis. Int J Cardiol. 2015;191:187-193.

79. Kelley WE, Januzzi JL, Christenson RH. Increases of cardiac troponin in conditions other than acute coronary syndrome and heart failure. Clin Chem. 2009;55(12):2098-2112.

80. Torbicki A, Kurzyna M, Kuca P, et al. Detectable serum cardiac troponin $\mathrm{T}$ as a marker of poor prognosis among patients with chronic precapillary pulmonary hypertension. Circulation. 2003;108(7):844-848.

81. Januzzi JL Jr, Filippatos G, Nieminen M, Gheorghiade M. Troponin elevation in patients with heart failure: on behalf of the third Universal Definition of Myocardial Infarction Global Task Force: Heart Failure Section. Eur Heart J. 2012;33:2265-2271.

82. Stacy SR, Suarez-Cuervo C, Berger Z, et al. Role of troponin in patients with chronic kidney disease and suspected acute coronary syndrome a systematic review. Ann Intern Med. 2014;161(7):502-512.

83. Fedullo PF, Tapson VF. Clinical practice: the evaluation of suspected pulmonary embolism. N Engl J Med. 2003;349(13):1247-1256.

84. Wells PS, Anderson DR, Ginsberg J. Assessment of deep vein thrombosis or pulmonary embolism by the combined use of clinical model and noninvasive diagnostic tests. Semin Thromb Hemost. 2000;26(6):643-656.

85. Kruip MJ, Slob MJ, Schijen JH, van der Heul C, Büller HR. Use of a clinical decision rule in combination with D-dimer concentration in diagnostic workup of patients with suspected pulmonary embolism: a prospective management study. Arch Intern Med. 2002;162(14):1631-1635.

86. van Belle A, Büller HR, Huisman MV, et al. Effectiveness of managing suspected pulmonary embolism using an algorithm combining clinical probability, D-dimer testing, and computed tomography. JAMA. 2006;295(2):172-179.

87. Konstantinides SV, Torbicki A, Agnelli G, et al. 2014 ESC guidelines on the diagnosis and management of acute pulmonary embolism. Eur Heart J. 2014;35(43):3033-3069, 3069a-3069k.

88. van Strijen MJ, de Monyé W, Kieft GJ, et al. Diagnosis of pulmonary embolism with spiral CT as a second procedure following scintigraphy. Eur Radiol. 2003;13(7):1501-1507.

89. Chopra N, Doddamreddy P, Grewal H, Kumar PC. An elevated D-dimer value: a burden on our patients and hospitals. Int J Gen Med. 2012;5:87-92.

90. Righini M, Le Gal G, Aujesky D, et al. Diagnosis of pulmonary embolism by multidetector CT alone or combined with venous ultrasonography of the leg: a randomised non-inferiority trial. Lancet. 2008;371(9621):1343-1352.

91. Righini M, Perrier A, De Moerloose P, Bounameaux H. D-dimer for venous thromboembolism diagnosis: 20 years later. JThromb Haemost. 2008;6(7):1059-1071.

92. Wilson DB, Gard KM. Evaluation of an automated, latex-enhanced turbidimetric D-dimer test (advanced D-dimer) and usefulness in the exclusion of acute thromboembolic disease. Am J Clin Pathol. 2003;120(6):930-937.

93. Pieper CF, Rao KM, Currie MS, Harris TB, Cohen HJ. Age, functional status, and racial differences in plasma D-dimer levels in communitydwelling elderly persons. J Gerontol A Biol Sci Med Sci. 2000. 55(11):M649-M657.

94. Leung AN, Bull TM, Jaeschke R, et al. An official American Thoracic Society/Society of Thoracic Radiology clinical practice guideline: evaluation of suspected pulmonary embolism. Am J Respir Crit Care Med. 2001;184(10):1200-1208.

95. Kelly AM. Can VBG analysis replace ABG analysis in emergency care? Emerg Med J. 2016;33(2):152-154.

96. Raffin TA. Diagnostic decision: indications for arterial blood gas analysis. Ann Intern Med. 1986;105(3):390-398. 
97. Celli BR, MacNee W. Standards for the diagnosis and treatment of patients with COPD: a summary of the ATS/ERS position paper. Eur Respir J. 2004;23(6):932-946.

98. Nieminen MS, Böhm M, Cowie MR, et al. Executive summary of the guidelines on the diagnosis and treatment of acute heart failure: the Task Force on Acute Heart Failure of the European Society of Cardiology. Eur Heart J. 2005;26(4):384-416.

99. Burri E, Potocki M, Drexler B, et al. Value of arterial blood gas analysis in patients with acute dyspnea: an observational study. Crit Care. 2011;15(3):R145.

100. Byrne AL, Bennett M, Chatterji R, Symons R, Pace NL, Thomas PS. Peripheral venous and arterial blood gas analysis in adults: are they comparable? A systematic review and meta-analysis. Respirology. 2014;19(2):168-175.

101. Kelly AM, Kyle E, McAlpine R. Venous $\mathrm{pCO}_{2}$ and $\mathrm{pH}$ can be used to screen for significant hypercarbia in emergency patients with acute respiratory disease. J Emerg Med. 2002;22(1):15-19.

102. Adrogué HJ, Rashad MN, Gorin AB, Yacoub J, Madias NE. Assessing acid-base status in circulatory failure: differences between arterial and central venous blood. $N$ Engl J Med. 1989;320(20):1312-1316.

103. Weinberg EO, Shimpo M, De Keulenaer GW, et al. Expression and regulation of ST2, an interleukin-1 receptor family member, in cardiomyocytes and myocardial infarction. Circulation. 2002; 106(23):2961-2966.

104. Januzzi JL Jr, Peacock WF, Maisel AS, et al. Measurement of the interleukin family member ST2 in patients with acute dyspnea: results from the PRIDE (Pro-Brain Natriuretic Peptide Investigation of Dyspnea in the Emergency Department) study. J Am Coll Cardiol. 2007;50(7):607-613.
105. Benoit JL, Hicks CW, Engineer RS, Hart KW, Lindsell CJ, Peacock WF. ST2 in emergency department patients with noncardiac dyspnea. Acad Emerg Med. 2013;20(11):1207-1210.

106. Dieplinger B, Egger M, Haltmayer M, et al. Increased soluble ST2 predicts long-term mortality in patients with stable coronary artery disease: results from the Ludwigshafen risk and cardiovascular health study. Clin Chem. 2014;60(3):530-540.

107. Brown AM, Wu AH, Clopton P, Robey JL, Hollander JE. ST2 in emergency department chest pain patients with potential acute coronary syndromes. Ann Emerg Med. 2007;50(2):153-158, 158.e1.

108. Martinez-Rumayor A, Camargo CA, Green SM, Baggish AL, O’Donoghue M, Januzzi JL. Soluble ST2 plasma concentrations predict 1-year mortality in acutely dyspneic emergency department patients with pulmonary disease. Am J Clin Pathol. 2008;130(4):578-584.

109. Oshikawa K, Kuroiwa K, Tago K, et al. Elevated soluble ST2 protein levels in sera of patients with asthma with an acute exacerbation. Am J Respir Crit Care Med. 2001;164(2):277-281.

110. Silvers SM, Howell JM, Kosowsky JM, Rokos IC, Jagoda AS. Clinical policy: critical issues in the evaluation and management of adult patients presenting to the emergency department with acute heart failure syndromes. Ann Emerg Med. 2007;49(5):627-669.
Open Access Emergency Medicine

\section{Publish your work in this journal}

Open Access Emergency Medicine is an international, peer-reviewed, open access journal publishing original research, reports, editorials, reviews and commentaries on all aspects of emergency medicine. The manuscript management system is completely online and includes a very quick and fair peer-review system, which is all easy to use.

\section{Dovepress}

Visit http://www.dovepress.com/testimonials.php to read real quotes from published authors. 